\title{
Biji Kebiul (Caesalpinia Bonduc L. Roxb) sebagai Adsorben Logam Besi (Fe)
}

\author{
Kebiul Seed (Caesalpinia Bonduc L. Roxb) as Adsorbent of Iron (Fe)
}

\author{
Muhammad Salman Alfarisi ${ }^{*}$, Ade Oktasari ${ }^{2}$, Dwi Fitriyani ${ }^{3}$ \\ ${ }^{1,2,3}$ Program Studi Kimia, Fakultas Sains Dan Teknologi, UIN Raden Fatah Palembang, \\ *corr-author: alfarisisalman047@gmail.com
}

\begin{abstract}
ABSTRAK
Logam berat merupakan limbah pencemar yang sulit terdegradasi di alam serta membutuhkan waktu yang lama untuk terurai. Proses adsorpsi dapat digunakan sebagai penanganan untuk logam berat Fe yang merupakan salah satu logam berat yang berasal dari limbah. Tujuan penelitian ini untuk mengetahui pengaruh waktu kontak serta konsentrasi logam Fe terhadap adsorben biji kebiul. Penelitian ini menggunakan metode Chesson untuk mengetahui kadar selulosa, hemiselulosa dan lignin dengan hasil uji pada biji kebiul dengan nilai rata-rata secara berurutan sebesar $19,53 \%, 23,3 \%$, dan 8,97\% dan kulit buah kebiul sebesar 30,84\%, 25,85\% dan 14,76\%. Hasil penelitian variasi waktu kontak 5, 10, 30, 50, 70, 100 menit waktu optimum tercapai pada menit ke-10 dengan Fe yang teradsorpsi sebesar 2,362 mg/g. Pada variasi konsentrasi logam Fe mencapai titik optimum pada 60 ppm dengan variasi 15, 35, 60, 80, 90, 100 ppm serta waktu kontak 10 menit dengan nilai kadar adsorpsi logam $\mathrm{Fe} 99,68 \%$.
\end{abstract}

\section{Kata-kata kunci : Adsorben, Aktivasi, Fe, Kebiul}

\section{ABSTRACT}

Heavy metal is a pollutant waste that is difficult to degrade in nature and takes a long time to decompose. The adsorption process can be used as a treatment for heavy metal Fe which is one of the heavy metals that comes from waste. The purpose of this study was to determine the effect of contact time and concentration of Fe metal on the adsorbent of kebiul seeds. This study used the method Chesson to determine the levels of cellulose, hemicellulose, and lignin with the results of the test on kebiul seeds with an average value of $19.53 \%, 23.3 \%$, and $8.97 \%$. Respectively and the peel of the kebiul fruit of $30.84 . \%$, $25.85 \%$ and $14.76 \%$. The results of the study of variations in contact time of 5, 10,30, 50, 70, 100 minutes, the optimum time was reached in the $10 \mathrm{th}$ minute with $2,362 \mathrm{mg} / \mathrm{g}$ of adsorbed $\mathrm{Fe}$. In variations of the concentration of Fe metal reached the optimum point at $60 \mathrm{ppm}$ with variations of 15,35, 60,80,90, $100 \mathrm{ppm}$ and a contact time of 10 minutes with an adsorption value of $99.68 \% \mathrm{Fe}$.

\section{Keywords: Adsorbent, Activation, Fe, Kebiul}

\section{PENDAHULUAN}

Pencemaran lingkungan oleh industri yang berupa limbah zat organik ataupun logam berat menjadi suatu permasalahan yang sangat penting untuk diperhatikan (Elysabeth, Jufrodi and Hudaeni, 2015). Logam berat merupakan limbah pencemar yang sulit terdegradasi di alam serta membutuhkan waktu yang lama untuk menguraikannya (Fitriah 
et al., 2019). Beberapa logam berat penyebab pencemaran perairan yang berbahaya diantaranya tembaga $(\mathrm{Cu})$, seng $(\mathrm{Zn})$, timbal $(\mathrm{Pb})$, merkuri $(\mathrm{Hg})$, Krom $(\mathrm{Cr})$ dan besi $(\mathrm{Fe})$. Besi merupakan salah satu logam berat yang bersifat toksik bagi lingkungan, karena besi dapat menyebabkan terjadinya perubahan rasa, bau, warna dan kekeruhan terhadap air yang tercemar (Darmayanti, Rahman and Supriadi, 2012).

Penanganan logam berat dapat menggunakan beberapa proses seperti pertukaran ion, presipitasi, netralisasi, biosorpsi, dan adsorpsi. Metode adsorpsi adalah metode yang lebih efisien, sederhana, biaya relatif murah, dapat bekerja dalam konsentrasi rendah, sehingga lebih mudah dilakukan daripada metode yang lain (Elysabeth, Jufrodi and Hudaeni, 2015). Pada metode adsorpsi dapat dilakukan dengan variasi waktu guna mengetahui waktu optimum adsoben menyerap adsorbat dan variasi konsentrasi untuk mendapatkan nilai konsentrasi optimum (Patri and Oktasari, no date). Metode adsorpsi dikenal dua istilah penting yaitu adsorben dan adsorbat. Adsorbat adalah zat yang teradsorpsi, sedangkan zat yang mengadsorpsi disebut adsorben (Hartini, 2014).

Adsorben dapat dibuat dari proses kimia maupun pemanfaatan material biologis atau alami seperti bahan-bahan alam yang mengandung selulosa (Surya, 2015). Salah satu tanaman yang diduga dapat digunakan sebagai adsorben adalah biji kebiul (Caesalpinia Bonduc L. Roxb). Tumbuhan kebiul tumbuh liar dan banyak ditemukan di Pulau Sumatera khususnya di daerah Bengkulu. Masyarakat Bengkulu menggunakan biji kebiul sebagai obat sakit perut, batu ginjal, kencing manis, dan hernia (Yuska Novi Yanty, Densi Selpia Sopianti, 2019).

Menurut Fitmawati (Hartanto, Sofiyanti and Artikel, 2014) tumbuhan dalam satu famili memiliki kesamaan morfologi dan kandungan senyawa yang hampir sama. Tanaman kedawung (Parkia roxburgii G. Don.) merupakan tanaman famili fabaceace dan satu famili dengan tanaman kebiul (Caesalpinia Bonduc L. Roxb). Biji Kedawung mengandung : karbohidrat 22,1\%(Danarto, 2011). Berdasarkan struktur biologisnya sel suatu tanaman baik daun atau biji memiliki dinding sel yang tersusun dari lignoselulosa (polisakarida dari karbohidrat). Lignoselulosa terdiri dari selulosa dan lignin (Azhar, 2016)(Millati et al., 2011). Selulosa dan lignin yang terkandung dalam dinding sel biji kebiul dapat digunakan dalam pembuatan adsorben logam Fe (Bahtiar et al., 2016)(Mandasari and Purnomo, 2016). Selulosa, hemiselulosa dan lignin adalah senyawa yang berperan penting dalam proses adsorpsi karena mengandung gugus aktif hidroksil $(\mathrm{OH})$ pada selulosa, asam karboksilat $(\mathrm{COOH})$ pada hemiselulosa dan karbonil $(-\mathrm{C}=\mathrm{O})$ pada lignin yang dapat menyerap logam Fe [14](Oktasari, 2016)(Zaini, 2017). Penelitian terkait kandungan biji kebiul hingga saat ini hanya sebatas pemanfaatan senyawa metabolit sekunder, sedangkan belum ada data tentang kandungan metabolit primer biji kebiul seperti selulosa, hemiselulosa dan lignin. Oleh karena itu, penelitian ini bertujuan untuk mengetahui kadar selulosa, hemiselulosa dan lignin, pengaruh waktu kontak adsorben biji kebiul terhadap logam Fe dan pengaruh konsentrasi logam Fe terhadap adsorben biji kebiul.

\section{METODE PENELITIAN}

\section{Alat dan Bahan}

Alat yang digunakan dalam penelitian ini adalah oven Memmert UN55, neraca analitik ohaus, gelas beker pyrex, pipet ukur pyrex, pipet tetes, spatula, kertas saring, kondensor, cawan porselin, mortar, alu, blender, shaker, ALPHA II Compact Bruker FT-IR Spektrofotometer, AAS Thermo Scientific ICE 3500 Vacum generator. Sementara itu, bahan yang digunakan dalam penelitian ini adalah biji kebiul diperoleh dari Kabupaten Bengkulu Selatan, $\mathrm{NaOH} 6 \%$ (p.a E. Merck), aquades, asam sulfat. 


\section{Prosedur}

a. Preparasi Sampel

Biji kebiul dihaluskan setelah itu, diayak dengan jaring berukuran 120 mesh. Selanjutnya, serbuk biji kebiul dianalisis menggunakan instrumen FTIR untuk mengetahui gugus fungsinya.

\section{b. Metode Chesson}

Satu gram sampel kering (berat a) ditambahkan $150 \mathrm{~mL}$ aquadest dan direfluks pada suhu $100^{\circ} \mathrm{C}$ dengan penangas air selama 1 jam. Hasilnya disaring dan residu dicuci dengan air panas $300 \mathrm{~mL}$. Residu kemudian dikeringkan dengan oven sampai beratnya konstan dan kemudian ditimbang (berat b). Residu ditambah $150 \mathrm{~mL} \mathrm{H}_{2} \mathrm{SO}_{4} 1 \mathrm{~N}$, kemudian dipanaskan menggunakan refluks selama 1 jam pada suhu $100^{\circ} \mathrm{C}$. Hasilnya disaring dan dicuci sampai netral dan residunya dikeringkan hingga beratnya konstan kemudian ditimbang (berat c). Residu kering ditambahkan $100 \mathrm{~mL} \mathrm{H}_{2} \mathrm{SO}_{4} 72 \%$ dan direndam pada suhu kamar selama 4 jam. Ditambahkan $150 \mathrm{~mL} \mathrm{H}_{2} \mathrm{SO}_{4} 1 \mathrm{~N}$ dan direfluks pada suhu $100^{\circ} \mathrm{C}$ dengan waterbath selama 1 jam pada pendingin balik. Residu disaring dan dicuci dengan aquadest sampai netral. Residu kemudian dipanaskan dengan oven dengan suhu $105^{\circ} \mathrm{C}$ sampai beratnya konstan dan ditimbang (berat d). Selanjutnya residu diabukan dan ditimbang (berat e).

\section{c. Aktivasi Serbuk Biji Kebiul}

Serbuk biji kebul direndam dengan $\mathrm{NaOH} 6 \%$ dan dikocok menggunakan shaker. Kemudian dibilas hingga $\mathrm{pH}$ netral menggunakan aquades dan dilakukan penyaringan menggunakan kertas saring serta dikeringkan dalam oven hingga berat konstan, Selanjutnya serbuk biji kebiul dianalisis menggunakan instrumen FTIR untuk mengetahui gugus fungsinya.

d. Adsorpsi Logam Fe pada Biji Kebiul

- Variasi Waktu Kontak

Proses adsorpsi dilakukan dengan memasukkan 0,1 gram serbuk biji kebiul ke dalam erlenmeyer yang telah berisi $25 \mathrm{ml}$ larutan logam Fe 10 ppm dengan variasi kontak yang digunakan 0 menit, 5 menit, 10 menit, 30 menit, 50 menit, 70 menit, 100 menit.

- Variasi Konsentrasi Logam Fe

Proses ini dilakukan dengan variasi konsentrasi logam Fe sebesar 15 ppm, 35 ppm, 60 ppm, 80 ppm, 90 ppm dan 100 ppm masing-masing ditambahkan adsorben serbuk biji kebiul yang teraktivasi sebanyak 0,1 gr. Larutan tersebut kemudian di kocok menggunakan shaker selama 10 menit (waktu optimum) pada suhu kamar, kemudian larutan disaring dengan kertas saring dan filtratnya diukur menggunakan AAS.

\section{HASIL DAN PEMBAHASAN}

\section{Analisis Kandungan Selulosa, Hemiselulosa dan Lignin Biji Kebiul}

Analisis kandungan selulosa, hemiselulosa dan lignin biji kebiul (Caesalpinia Bonduc L. Roxb) dilakukan dengan metode Chesson untuk mengetahui kadarnya karena selulosa, hemiselulosa dan lignin merupakan kelompok karbohidrat yang penting dalam pembuatan adsorben. Ketiga senyawa ini memiliki ciri khusus pada strukturnya sehingga dapat dibedakan. Selulosa mempunyai gugus fungsi hidroksil $(\mathrm{OH})$, hemiselulosa memiliki gugus fungsi asam karboksilat $(\mathrm{COOH})$ sedangkan gugus fungsi lignin ialah karbonil ($\mathrm{C}=\mathrm{O}$ ). Gugus-gugus ini berperan sebagai pengikat logam berat dalam larutan melalui interaksi pertukaran ion atau pembentukan kompleks. Hasil analisis komponen selulosa dan hemiselulosa biji kebiul (Caesalpinia Bonduc L. Roxb) dapat dilihat pada Tabel 1. 
Tabel 1. Kandungan komponen kulit biji kebiul (A) dan kulit buah kebiul (B)

\begin{tabular}{cccc}
\hline Komponen & Selulosa & Hemiselulosa & Lignin \\
\hline A & $19,53 \%$ & $23,2 \%$ & $8,975 \%$ \\
B & $30,84 \%$ & $25,85 \%$ & $14,76 \%$ \\
\hline
\end{tabular}

Tabel 1 menunjukkan bahwa komponen penyusun biji kebiul paling tinggi terdapat pada kulit buah yang memiliki kandungan selulosa sebesar 30,84\%. Menurut Tellu (2008) kadar selulosa tertinggi terdapat pada bagian kulit pada suatu tumbuhan.

\section{Pengaruh Aktivasi dan Karakterisasi pada Adsorben}

Berdasarkan hasil analisis kandungan selulosa, hemiselulosa dan lignin kulit buah digunakan sebagai adsorben karena memiliki kadar selulosa tertinggi dan dilanjutkan ke tahap aktivasi. Pada proses aktivasi, kulit buah kebiul dihaluskan menjadi serbuk berukuran 120 mesh.

Serbuk kulit buah kebiul hasil penghalusan kemudian diaktivasi menggunakan $\mathrm{NaOH} 6 \%$. Hal ini berguna untuk memecah lignoselulosa, mengurangi kandungan lignin dan hemiselulosa serta meningkatkan porositas bahan uji Devi (2019). Pelarut $\mathrm{NaOH} 6 \%$ memiliki kemampuan untuk mengurangi kadar lignin yang telah dibuktikan pada penelitian Devi (2019) dengan menggunakan sampel pelepah salak dengan kadar lignin awal sebesar $20,05 \%$ menjadi $17,4 \%$. Mekanisme aktivasi menggunakan $\mathrm{NaOH}$ dalam memecah ikatan lignoselulosa dapat dilihat pada Gambar 1.

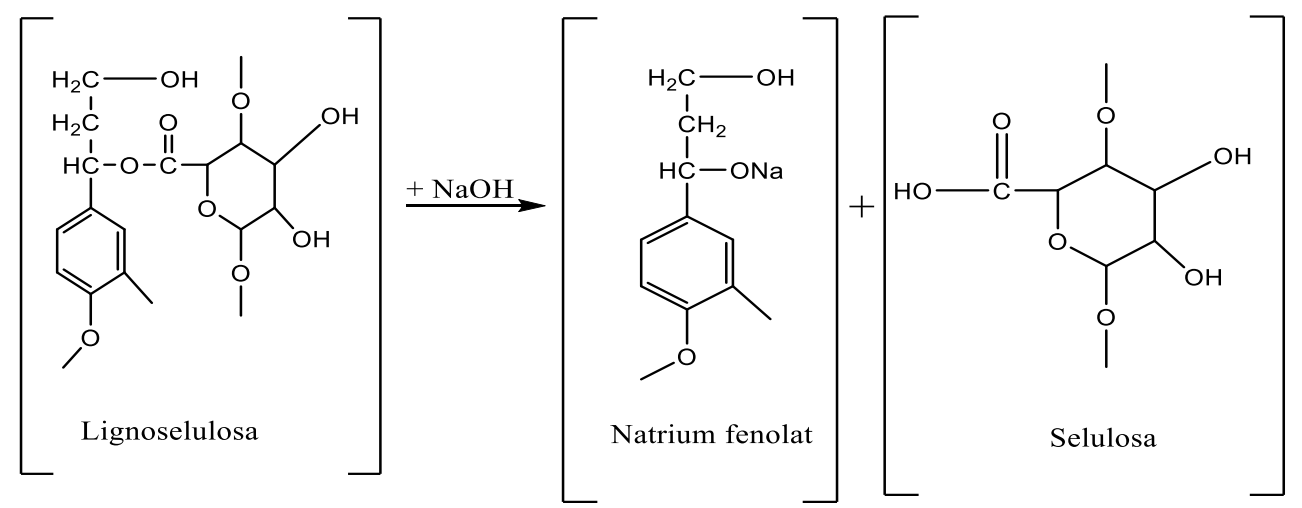

Gambar 1. Reaksi pemutusan ikatan lignoselulosa

Gambar 1 mendeskripsikan $\mathrm{NaOH}$ dapat merusak lignoselulosa dengan memecah ikatan ester antara selulosa dan lignin. Ion $\mathrm{OH}^{-}$dari $\mathrm{NaOH}$ akan memutuskan ikatan-ikatan dari struktur dasar lignoselulosa, sedangkan ion $\mathrm{Na}^{+}$akan membentuk natrium fenolat. Natrium fenolat ini bersifat mudah larut dalam air(Lena Rahmidar, Seruni Wahidiniawati, 2018).

Proses aktivasi dilakukan dengan penambahan larutan $\mathrm{NaOH}$ terhadap adsorben kulit buah kebiul dengan perbandingan (10:1), agar adsorben terendam seluruhnya dengan larutan $\mathrm{NaOH} 6 \%$. Kemudian diaduk menggunakan shaker. Fungsi pengadukan yakni agar permukaan adsorben terhomogenisasi dengan pelarut $\mathrm{NaOH} 6 \%$.

Setelah itu dibilas dengan aquades hingga $\mathrm{pH}$ netral. Penetralan ini berfungsi untuk meningkatkan efektivitas adsorben dalam penyerapan logam, karena $\mathrm{pH}$ yang tidak netral dapat menyebabkan zat aktivator menempel pada adsorben yang dapat menurunkan tingkat efektivitas dari adsorben tersebut (Ariyani, 2020). Selanjutnya, adsorben kulit buah kebiul disaring dan dioven pada suhu $105^{\circ} \mathrm{C}$ untuk menghilangkan kadar air. Menurut Kusdarini 
et al (2017) semakin rendah kadar air dapat memperluas permukaan pori pada adsorben. Adsorben kulit buah kebiul selanjutnya ditimbang untuk mengetahui massa adsorben setelah diaktivasi. Indikasi terlarutnya lignin ditandai dengan berkurangnya berat sampel setelah dilakukan proses aktivasi serta warna sampel yang berubah menjadi cerah. Berikut gambar perbedaan berat sampel dan warna sebelum dan sesudah dilakukan proses aktivasi (Gambar 2).
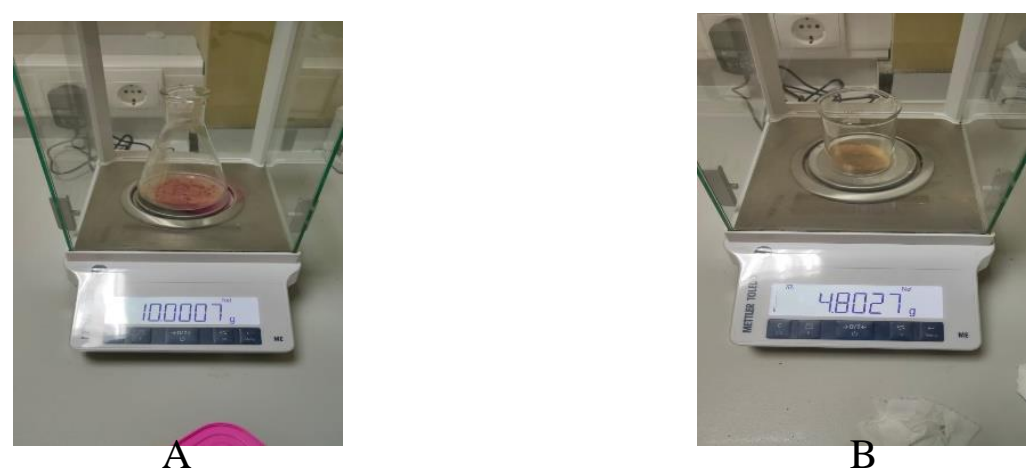

Gambar 2. Sampel kulit buah kebiul sebelum diaktivasi (A) dan sesudah aktivasi dengan $\mathrm{NaOH} 6 \%$ (B)

Pada Gambar 2 terlihat perbedaan tekstur, warna dan massa sebelum dan sesudah aktivasi kulit buah kebiul. Kulit buah kebiul setelah aktivasi memiliki tekstur lebih halus dan warna lebih cerah. Massa sebelum aktivasi sebesar 10 gr menjadi 4,8 gr setelah aktivasi. Hal ini disebabkan karena zat aktivator $\mathrm{NaOH}$, dimana $\mathrm{NaOH}$ berfungsi sebagai pelarut yang mampu melarutkan pengotor-pengotor yang terkandung dalam sampel yang tidak dibutuhkan pada proses adsorpsi seperti hemiselulosa, lignin dan pektin sehingga pori pada adsorben lebih terbuka permukaannya (Udin, 2015).

Konfirmasi gugus-gugus fungsi yang terdapat pada adsorben biji kebiul dengan cara karakterisasi menggunakan FTIR. Analisis menggunakan instrumen FTIR dilakukan untuk mengetahui gugus fungsi yang terdapat pada biji kebiul yang telah dihaluskan dan setelah diaktivasi menggunakan $\mathrm{NaOH}$ 6\%. Hasil analisis menggunakan instrumen FTIR sebelum dan sesudah pengaktivasian pada biji kebiul dapat dilihat pada Gambar 3.

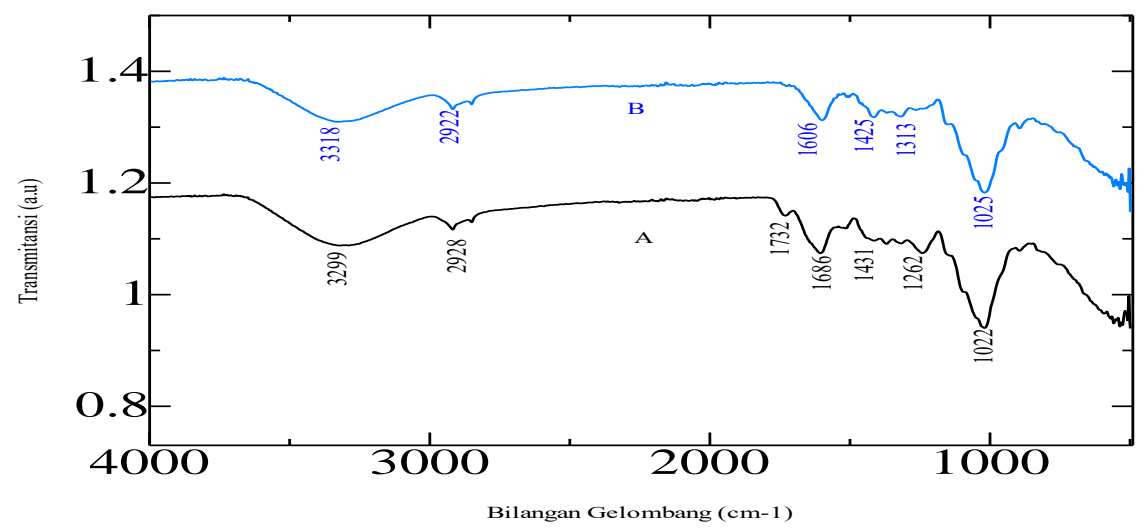

\section{Gambar 3. Spektra FT-IR kulit buah kebiul sebelum aktivasi (A) dan setelah aktivasi dengan $\mathrm{NaOH} 6 \%$ (B)}

Pada Gambar 3 spektra IR menunjukkan pergeseran serapan pada gugus hidroksil (- 
$\mathrm{OH})$ dari panjang gelombang $3229 \mathrm{~cm}^{-1}$ menjadi $3318 \mathrm{~cm}^{-1}$. Puncak pada $2928 \mathrm{~cm}^{-1}$ dan $1431 \mathrm{~cm}^{-1}$ menunjukkan vibrasi gugus alkil $(-\mathrm{CH})$ dari $\left(-\mathrm{CH}_{3}\right)$ alifatik. Puncak yang teramati pada $1022 \mathrm{~cm}^{-1}$ (tajam) berkaitan dengan vibrasi ulur C-O dari alkohol (-OH) dan asam karboksilat $(\mathrm{COOH})$ yang menunjukkan keberadaan hemiselulosa.

Keberadaan gugus fungsi pada adsorben biji kebiul setelah diaktivasi dapat dilihat dari hasil spektra IR pada gambar 8 (B) menunjukkan vibrasi ulur $-\mathrm{OH}$ mengalami pergeseran bilangan gelombang $3299 \mathrm{~cm}^{-1}$ menjadi $3318 \mathrm{~cm}^{-1}$. Pemutusan lignin dari selulosa yang diperkuat dengan tidak munculnya serapan pada bilangan gelombang 1732 $\mathrm{cm}^{-1}$ yang merupakan ikatan ester (RCOOR) yang telah putus setelah diaktivasi dengan $\mathrm{NaOH}$ (Barman et al., 2020)(Oktasari, 2016). Hal ini mampu mengindikasikan bahwa senyawa aktivator $\mathrm{NaOH}$ terbukti mampu memutuskan ikatan ester pada lignoselulosa dan dapat mengurangi kadar lignin.

\section{Pengaruh Waktu Kontak Adsorpsi Logam Fe}

Waktu kontak ditentukan untuk mengetahui waktu optimal yang dibutuhkan adsorben biji kebiul dalam mengadsorpsi logam Fe secara maksimal. Waktu kontak merupakan hal yang menentukan dalam proses adsorpsi. Variasi waktu kontak yang digunakan yaitu 5, 10, 30, 50, 70, 100 menit menggunakan konsentrasi larutan Fe 10 ppm. Pada hasil uji penentuan waktu kontak optimum gambar 9 didapatkan hasil kadar logam $\mathrm{Fe}$ yang tersisa setelah mengalami adsorpsi. Setelah didapatkan hasil tersebut dapat dihitung kapasitas adsorpsinya, sehingga diperoleh data kapasitas adsorpsi adsorben logam Fe yang dapat dilihat pada Gambar 4.

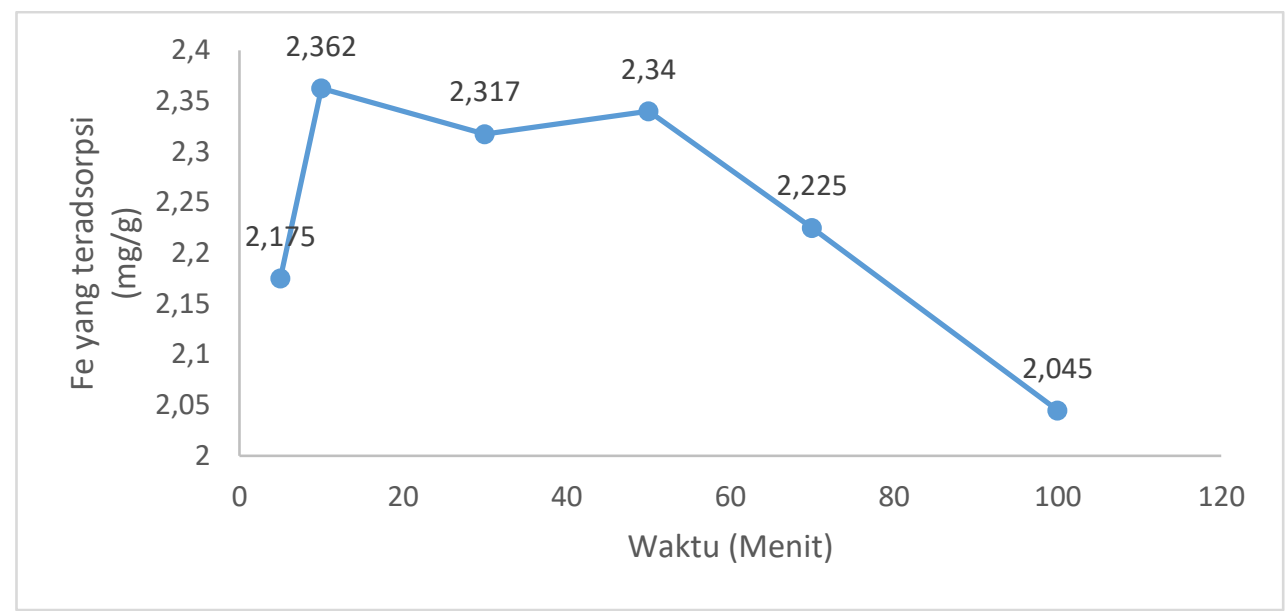

Gambar 4. Grafik pengaruh waktu terhadap adsorpsi Fe

Gambar 4 menunjukkan bahwa waktu kontak dapat mempengaruhi jumlah ion logam Fe yang terserap. Pada proses adsorpsi semakin lama waktu kontak dapat menurunkan kadar pada larutan logam Fe. Namun, pada penelitian ini waktu optimum penyerapan adsorbat pada adsorben di capai pada menit ke-10 dan mengalami penurunan daya serap pada menit 30 dan mengalami peningkatan pada menit 50. Hal ini dikarenakan fenomena pada adsorpsi fisika yang bersifat reversible dan terjadi relatif cepat yang menyebabkan pemutusan/pengikatan antara ion logam dan adsorben yang disebabkan ikatannya yang lemah dan dapat kembalinya ion logam pada larutan (Solika, Napitupulu and Gonggo, 2018). Pada menit 70 dan 100 terjadinya penurunan daya serap yang disebabkan lamanya waktu kontak yang terjadi yang menyebabkan ion logam kembali pada larutan, fenomena ini disebut desorpsi. Hal ini sesuai dengan penelitian Jubilate et al (2016) 
yang mengemukakan titik kesetimbangan adsorben kontak dengan adsorbat pada variasi waktu 5, 10, 30, 60 menit tercapai pada menit ke-10 dimana menit ke-5 belum mencapai titik kesetimbangan dikarenakan adsorben masih memiliki rongga kosong yang belum diisi oleh adsorbat. Pada menit 30 dan 60 mengalami desorpsi terjadinya proses desorpsi karena permukaan adsorben telah jenuh sehingga tidak mampu untuk berinteraksi dengan ion logam $\mathrm{Fe}$ sehingga akan berpengaruh terhadap nilai efisiensi adsopsi.

\section{Pengaruh Variasi Konsentrasi Logam Fe terhadap Adsorben}

Variasi konsentrasi dilakukan untuk mengetahui nilai kapasitas adsorpsi dari adsorben terhadap logam Fe Hasil uji variasi konsentrasi pada logam Fe dapat dilihat pada Gambar 5 diperoleh kadar logam Fe yang tersisa setelah proses adsorpsi.

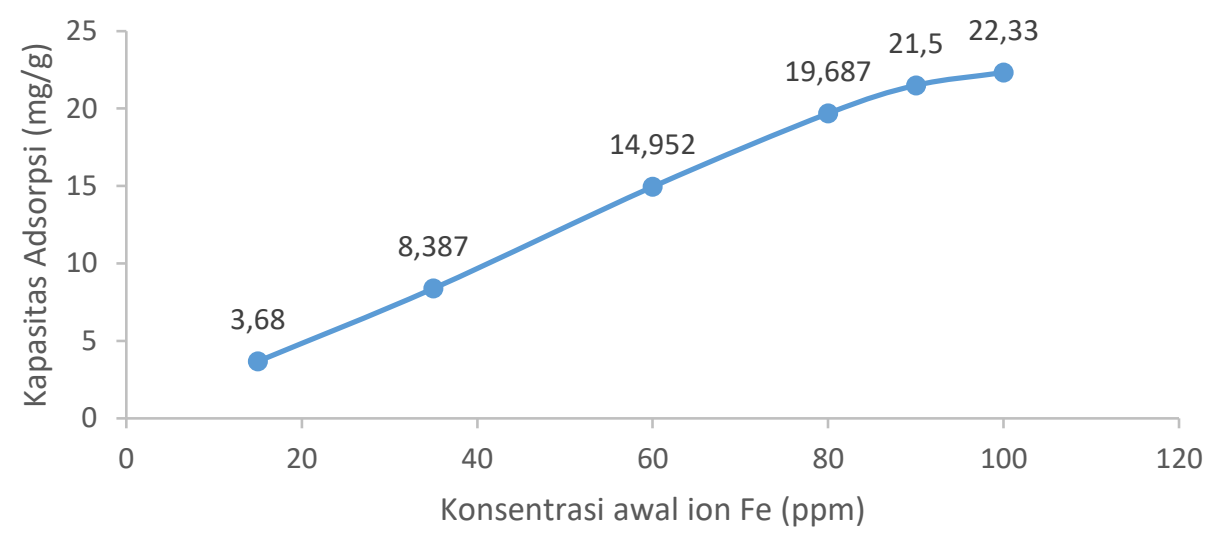

Gambar 5. Grafik pengaruh konsentrasi awal larutan Fe

Pada Gambar 5 menunjukkan kapasitas adsorpsi logam Fe yang teradsorpsi oleh adsorben biji kebiul mengalami peningkatan dari variasi 15 ppm sampai 100 ppm. Kapasitas adsorpsi terbesar diperoleh pada konsentrasi 100 ppm dengan nilai sebesar 22,33 $\mathrm{mg} / \mathrm{g}$. Semakin tinggi konsentrasi ion logam maka kapasitas adsorpsi adsorben terhadap adsorbat akan meningkat. Jika konsentrasi ion logam meningkat maka ion dalam larutan akan semakin banyak sehingga meningkatkan ion logam yang berinteraksi dengan sisi aktif adsorben. Hasil penelitian ini sesuai dengan penelitian Zubaidah et al (2017) mengemukakan jika konsentrasi adsorbat meningkat maka semakin banyak adsorbat yang teradsorpsi yang menyebabkan kapasitas adsorpsinya semakin meningkat.

Dari hasil uji kapasitas adsorpsi pada adsorben biji kebiul dapat juga dihitung persentase logam Fe yang teradsorpsi oleh adsorben tersebut, sehingga diperoleh data pada gambar 6. 


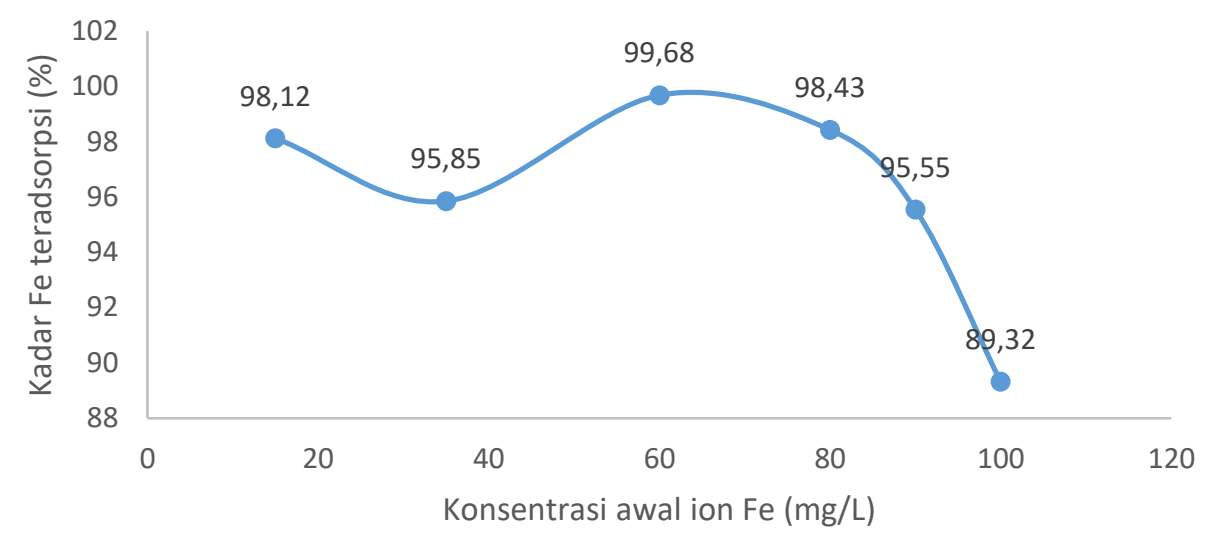

Gambar 6. Persentase logam Fe yang terserap oleh adsoben kulit buah kebiul

Gambar 6 menunjukkan bahwa konsentrasi mempengaruhi nilai \%Fe teradsorpsi. Akan tetapi daya serap adsorben biji kebiul terhadap ion logam Fe dapat mengalami kenaikan dan penurunan yang disebabkan adanya pemutusan/pengikatan konsentrasi ion logam pada adsorben (Solika, Napitupulu and Gonggo, 2018). Hal ini terjadi karena ion logam dan adsorben memiliki ikatan yang lemah dimana molekul yang teradsorpsi bebas untuk menutupi seluruh permukaan adsorben (Solika, Napitupulu and Gonggo, 2018)(Anugrahwati, 2020). Pada gambar 11 persentase logam Fe yang terserap terbesar terdapat pada konsentrasi $60 \mathrm{ppm}$, karena telah terjadinya titik kesetimbangan antara adsorben biji kebiul dan ion logam Fe (Ginting, Syukur and Yulia, 2017). Konsentrasi 60 ppm memiliki selisih nilai cukup kecil dari konsentrasi sebelum dan sesudahnya mirip dengan kejadian yang disebut kesetimbangan dinamis antara laju adsorpsi dan desorpsi yaitu suatu kondisi ion logam $\mathrm{Fe}$ mencapai titik jenuh yang tidak dapat menyerap ion logam Fe kembali (Afrianita dan Dewilda, 2014).

\section{KESIMPULAN}

Berdasarkan hasil penelitian dapat diperoleh kesimpulan bahwa adsorpsi logam $\mathrm{Fe}$ dipengaruhi dengan lamanya waktu kontak penyerapan logam Fe oleh adsorben biji kebiul. Pada menit ke-10 telah terjadi titik jenuh adsorben untuk menyerap logam $\mathrm{Fe}$ dengan nilai adsorpsi 2,362 mg/g. Sementara itu, konsentrasi awal larutan Fe mempengaruhi kapasitas adsorpsi dan persentase penyerapan logam Fe oleh adsorben biji kebiul. Pada konsentrasi 100 ppm memiliki nilai kapasitas adsorpsi tertinggi sebesar $22,33 \mathrm{mg} / \mathrm{L}$ dan pada konsentrasi 60 ppm mempunyai effisiensi adsorpsi terbesar dengan nilai 99,68\%.

\section{UCAPAN TERIMA KASIH}

Penulis mengucapkan terima kasih kepada Kementerian Pendidikan, Kebudayaan, Riset, dan Teknologi (KEMDIKBUD DIKTI) dalam Program Talenta Inovasi Indonesia yang telah mendanai proses penelitian yang telah dilakukan.

\section{DAFTAR PUSTAKA}

Afrianita, R. and Dewilda, Y. (2014), Potensi Fly Ash Sebagai Adsorben Dalam Meyisihkan Logam Berat Cromium (Cr) Pada Limbah Cair Industri, J. Dampak, vol. 11, no. 1, p. 67.

Anugrahwati, M. (2020), Pemanfaatan Limbah Kulit Salak Pondoh (Salacca edulis) 
sebagai Komposit Karbon Aktif Termodifikasi untuk Adsorbsi Logam Timbal (Pb), Universitas Islam Indonesia : Yogyakarta.

Ariyani, R. et al. (2020), Pembuatan Arang Aktif Dari Ampas Tebu Dan Aplikasinya Sebagai Adsorben Zat Warna Merah dari Limbah Pencelupan Benang Tenun Sarung Samarinda, Universitas Mulawarman : Samarinda.

Azhar, M. (2016),Biomolekul sel, 1st ed : Padang

Bahtiar, E. T. et al. (2016), Pengaruh Komponen Kimia dan Ikatan Pembuluh terhadap Kekuatan Tarik Bambu, J. Tek. Sipil, vol. 23, no. 1, pp. 31-40.

Barman, D. N. et al. (2020), Deconstruction of Pine Wood (Pinus sylvestris) Recalcitrant Structure Using Alkali Treatment for Enhancing Enzymatic Saccharification Evaluated by Congo Red, Waste and Biomass Valorization, vol. 11, no. 5, pp. 17551764.

Danarto, S. A. (2011), Keragaman dan Potensi Koleksi Polong-Polongan (Fabaceae) di Kebun Raya Purwodadi, Fkip Uns, no. Tabel 1, pp. 1-7.

Darmayanti, D., Rahman, N. and Supriadi, S. (2012), Adsorpsi Timbal (Pb) Dan Zink (Zn) Dari Larutannya Menggunakan Arang Hayati (Biocharcoal) Kulit Pisang Kepok Berdasarkan Variasi Ph (Adsorption Of Plumbum (Pb) And Zinc (Zn) From Its The Solution By Using Biological Charcoal (Biocharcoal) Of Kepok Banana), J. Akad. Kim., vol. 1, no. 4, p. 224156.

Devi, D. et al. (2019), Kandungan Lignin, Hemiselulosa Dan Selulosa Pelepah Salak Pada Perlakuan Awal Secara Fisik Kimia dan Biologi, J. Ilm. Rekayasa Pertan. dan Biosist., vol. 7, no. 2, pp. 273-282.

Elysabeth, T., Jufrodi and Hudaeni (2015), Adsorbsi Logam Berat Besi dan Timbal Menggunakan Zeolit Alam Bayah Teraktivasi, J. Chemtech, vol. 1, no. 1, pp. 1-4.

Fitriah, I. et al. (2019), Potensi Bencana Dibalik Volume Sampah Anorganik Dalam Kegiatan Perkuliahahan, Bio Educ., vol. 4, no. 2, pp. 95-105.

Ginting, S. B., Syukur, S. D. and Yulia, Y. (2017), Kombinasi Adsorben Biji Kelor - Zeolit Alam Lampung untuk Meningkatkan Efektivitas Penjerapan Logam $\mathrm{Pb}$ dalam Air secara Kontinu pada Kolom Fixed Bed Adsorber, J. Rekayasa Proses, vol. 11, no. 1, p. 1.

Hartanto, S., Sofiyanti, N. and Artikel, I. (2014), Studi Etnobotani Famili Zingiberaceae dalam Kehidupan Masyarakat Lokal di Kecamatan Pangean Kabupaten Kuantan Singingi, Riau, Biosaintifika J. Biol. Biol. Educ., vol. 6, no. 2, pp. 98-108.

Hartini, L. (2014), Karakterisasi Karbon Aktif Teraktivasi NaCl Dari Ampas Tahu. Universitas Islam Negeri Maulana Malik Ibrahim : Malang.

Jubilate, F., Zaharah, T. A. and Syahbanu, I. (2016), Pengaruh Aktivasi Arang Dari Limbah Kulit Pisang Kepok Sebagai Adsorben Besi (II) Pada Air Tanah, J. Kim. Khatulistiwa, vol. 5, no. 4, pp. 14-21.

Kusdarini, E., Budianto, A. and Ghafarunnisa, D. (2017), Produksi Karbon Aktif Dari Batubara Bituminus Dengan Aktivasi Tunggal $\mathrm{H}_{3} \mathrm{PO}_{4}$, Kombinasi $\mathrm{H}_{3} \mathrm{PO}_{4}$ $\mathrm{NH}_{4} \mathrm{HCO}_{3}$, dan Termal, Reaktor, vol. 17, no. 2, pp. 74-80.

Lena Rahmidar, Seruni Wahidiniawati, T. S. (2018), Pembuatan Dan Karakterisasi Metil Selulosa Dari Bonggol Dan Kulit Nanas (Ananas Comosus), ISSN 2502-3632 ISSN 2356-0304 J. Online Int. Nas. Vol. 7 No.1, Januari - Juni 2019 Univ. 17 Agustus 1945 Jakarta, vol. 53, no. 9, pp. 88-96.

Mandasari, I. and Purnomo, A. (2016), Penurunan Ion Besi (Fe) dan Mangan (Mn) dalam Air dengan Serbuk Gergaji Kayu Kamper, J. Tek. ITS, vol. 5, no. 1, pp. 1-6. 
Millati, R. et al. (2011), Biological pretreatment: Review, BioResources, vol. 6, no. 4, pp. 5224-5259.

Oktasari, A. (2016), Kulit Kacang Tanah (Arachis Hypogaea L.) Sebagai Adsorben $\mathrm{Pb}(\mathrm{Ii}$ ), vol. 2, no. 1, pp. 17-27.

Patri, M. Y. and Oktasari, A. (2017) PEMANFAATAN KULIT KACANG TANAH (Arachis hypogaea L.) SEBAGAI ADSORBEN LOGAM BERAT KADMIUM, pp. $1-9$.

Solika, N., Napitupulu, M. and Gonggo, S. T. (2018), Bioadsorpsi Pb(Ii) Menggunakan Kulit Jeruk Siam (Citrus Reticulata), J. Akad. Kim., vol. 6, no. 3, p. 160.

Surya, S. A. (2015), Pemanfaatan limbah rambut manusia sebagai pelampung adsorben pencemaran minyak di lautan, Universitas Sebelas Maret : Surakatra.

Tellu, A. T. (2008), Sifat Kimia Jenis-jenis Rotan yang Diperdagangkan di Provinsi Sulawesi Tengah, Biodiversitas, vol. 9, no. 3.

Udin, Y. (2015), Biosorpsi Kadmium ( Cd ) Pada Serat Sabut Kelapa Hijau (Cocos Nucifera) Teraktivasi Natrium Hidroksida $(\mathrm{NaOH})$, Jur. Kim. Pada Fak. Sains Dan Teknol., no. Cd.

Yuska Novi Yanty, Densi Selpia Sopianti, C. V. (2019), Fraksinasi Dan Skrining Fraksi Biji Kebiul (Caesalpinia Bonduc (L) Roxb) Dengan Metode KLT (Kromatografi Lapis Tipis), Borneo J. Phamascientech, vol. 03Zaini, H. (2017) 'Penyisihan Pb(II) Dalam Air Limbah Laboratorium Kimia Sistem Kolom Dengan Bioadsorben Kulit Kacang Tanah', ETHOS (Jurnal Penelitian dan Pengabdian), (Ii), p. 8. doi: 10.29313/ethos.v0i0.2220.

Zubaidah, S., Khaldun, I. and Hanum, L. (2017), Uji Daya Serap Serbuk Gergaji Kayu Pinus (Pinus mercusii) Terhadap Logam Timbal (II) Menggunakan Metode Spektrofotometri Serapan Atom (SS) Abstrak, Prodi Kim. FKIP Univ. Syiah Kuala, Darussalam Banda Aceh, vol. 2, no. 2, pp. 107-116. 